\title{
The Comparison of the Effect of Memory Specificity Training, Behavioral Activation Treatment, and Cognitive Behavioral Therapy on Treatment-Resistant Depression
}

\author{
Rezvan Sadr Mohammadi, Simin Gholamrezaie*, Ezatolah Ghadampour
}

Department of Psychology, Lorestan University, Khoram Abad, Iran

\section{ABSTRACT}

Introduction: Treatment-resistant depression is a severe form of major depression that often fails with multiple treatments with standard antidepressants and has a poor long-term prognosis. The aim of this study was to compare the effect of memory specificity training, behavioral activation treatment, and cognitive behavioral therapy on treatment-resistant depression. Materials and Methods: This is a semi-experimental research with pre-test, post-test and follow-up with a control group. The participants are all patients with treatmentresistant depression in Rafsanjan, Iran. Sixty patients with treatment-resistant depression who referred to a psychiatrist and two psychologists in 2017 were selected. They were randomly divided into four groups of 15 persons; three experimental and one control groups. Data were collected by Beck depression, rumination and dysfunctional attitude questionnaire. Results: The results have shown a significant difference in the post-test depression of all three treatment groups compared to the control group. This difference was also evident in the follow-up phase. Furthermore, there was a significant difference in the rumination variable between the memory specificity training and behavioral activation in the post-test and followup stages. In addition, there was a significant difference in the attitude level between the memory specificity training and behavioral activation in the post-test phase and between the memory specificity training and cognitive-behavioral therapy and behavioral activation in the follow-up phase. Conclusion: According to the results, the use of psychotherapy, especially memory specificity training, is suggested as an effective psychological intervention in the management of treatment-resistant depression.

\section{Key words:}

1. Depression

2. Cognitive Behavioral Therapy

3. Psychotherapy

*Corresponding Author: Simin Gholamrezaie

E-mail: gholamrezaei_s@yahoo.com 


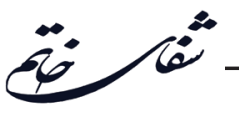

مقايسة اثربخشى آموزش اختصاصىسازى خاطرات، درمان فعالسازى رفتارى و درمان شناختى -رفتارى بر افسردَى مقاوم به درمان دمان فيان

رضوان صدرمحمدى، سيمين غلامرضايى"، عزت اله قدم يور

كروه روانشناسى، دانشَاه لرستان، خرم آباد، ايران

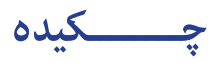

مقدمه: افسردگى مقاوم به درمان يك شكل شديد از افسردىى عمده است كه اغلب در درمانهاى متعدد

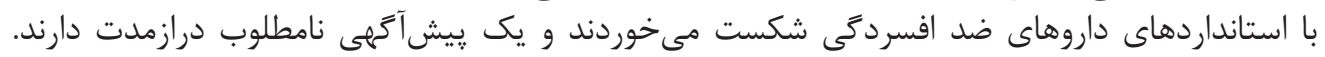

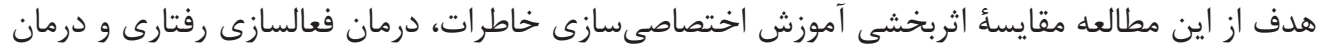

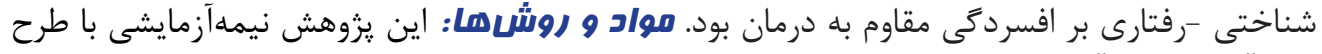

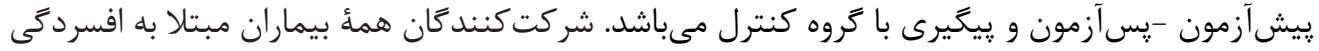

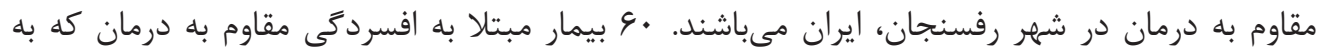

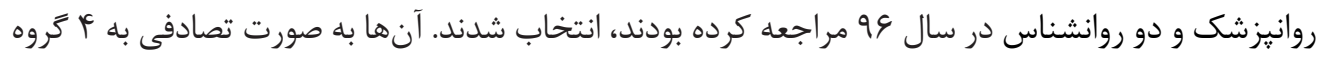

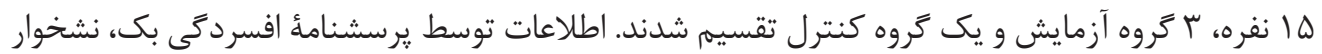

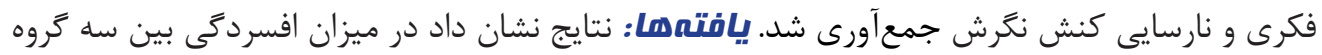

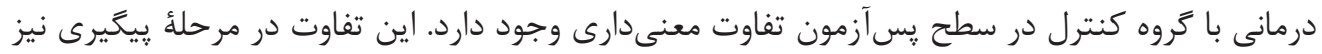

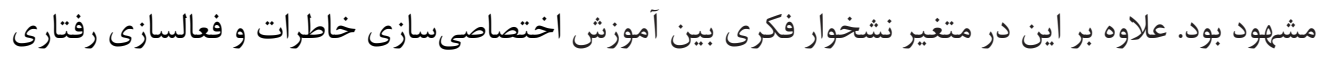

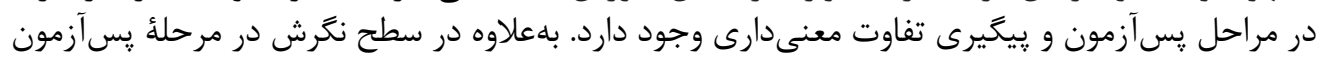

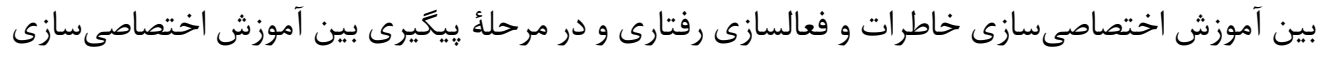

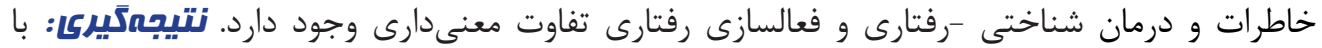

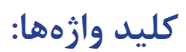

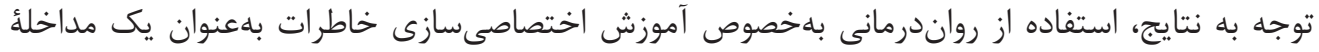

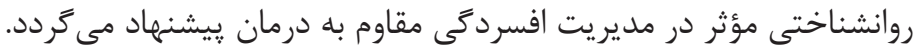

(1.

: r

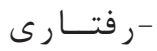

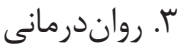

* نويسنده مسئول: سيمين غلامرضايى :

آدرس الكترونيكى: gholamrezaei_s@yahoo.com 


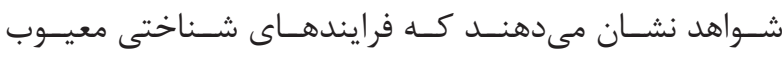

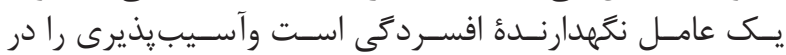

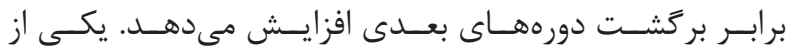

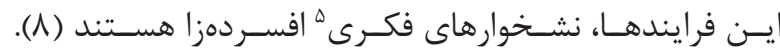

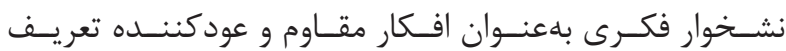

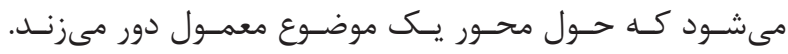

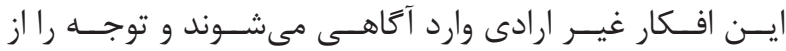

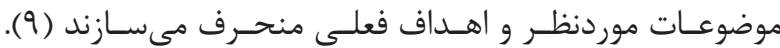

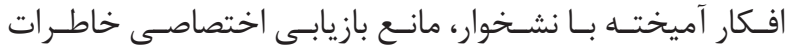

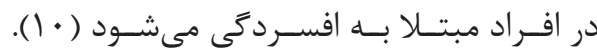

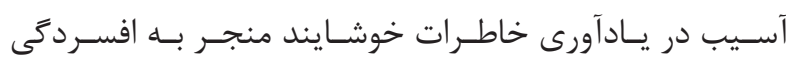

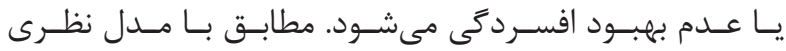

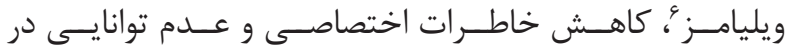

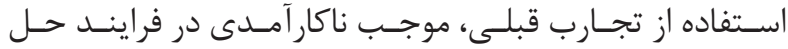

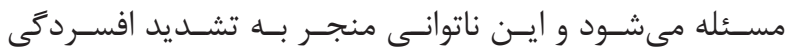

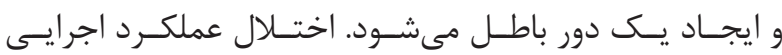

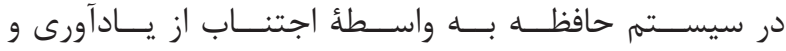

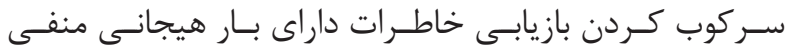

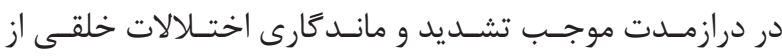

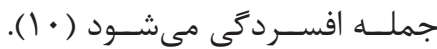

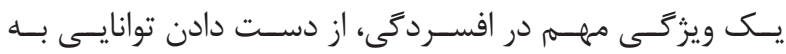

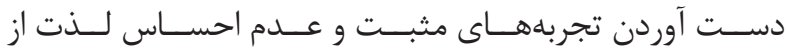

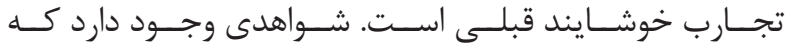

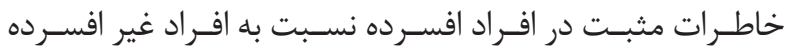

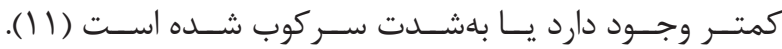

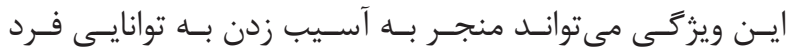

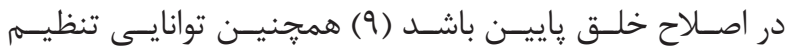

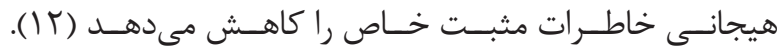

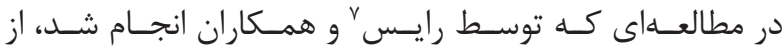

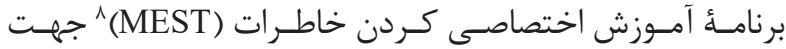

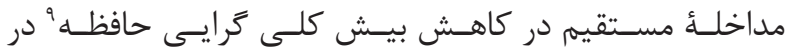

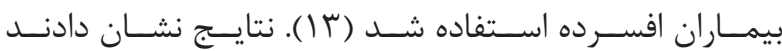

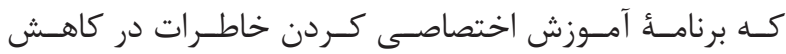

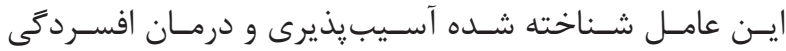

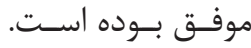

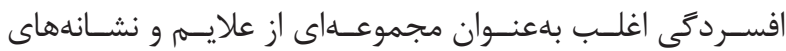

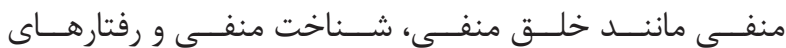

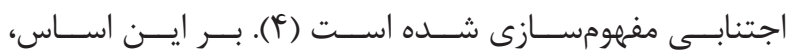

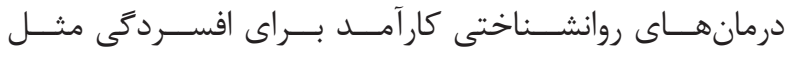

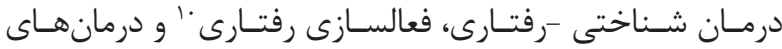

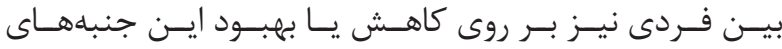

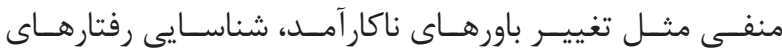

${ }^{1}$ Sequenced treatment alternatives to relieve depression

${ }^{2}$ Treatment resistant depression

${ }^{3}$ Cognitive-behavioral therapy

${ }^{4}$ Dysfunctional attitude

${ }^{5}$ Rumination

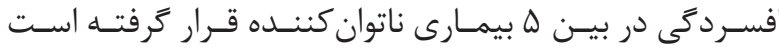

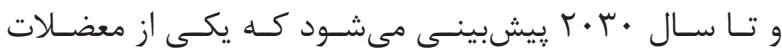

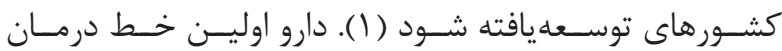

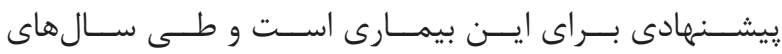

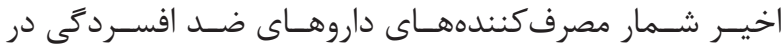

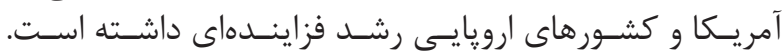

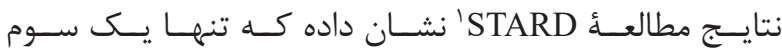

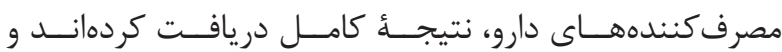

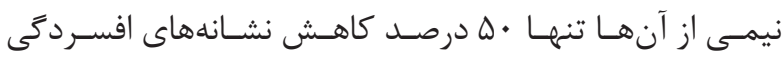

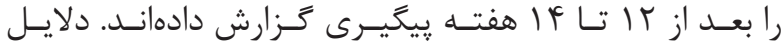

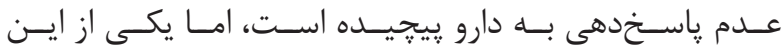

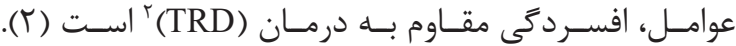
افسـرد

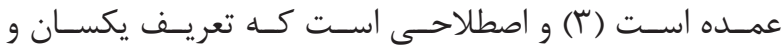

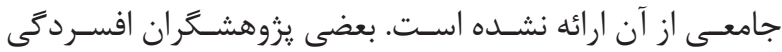

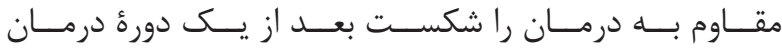

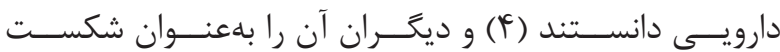

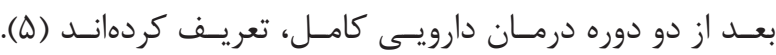

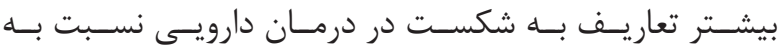

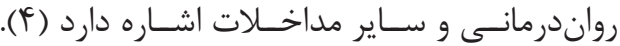

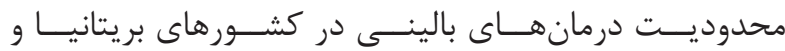

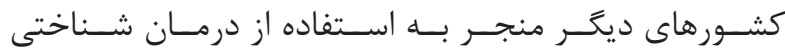

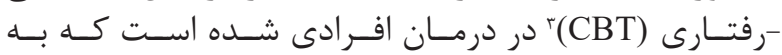

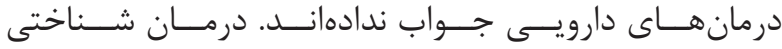

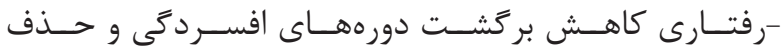

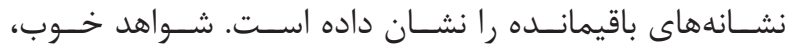

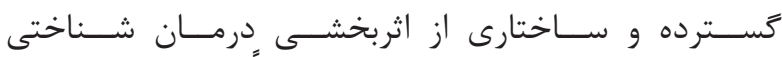

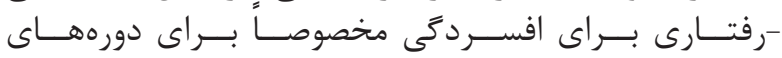

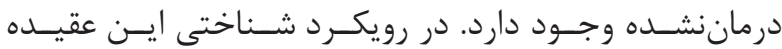

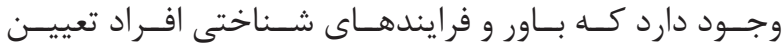

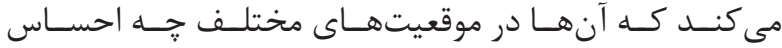

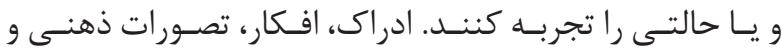

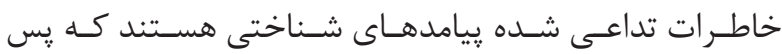

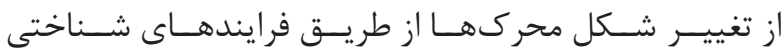

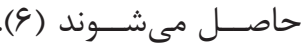

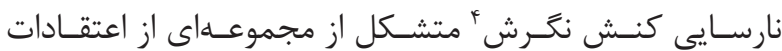

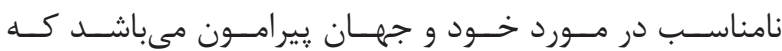

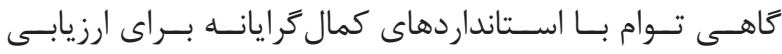

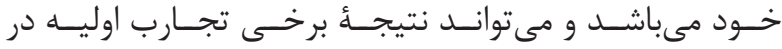

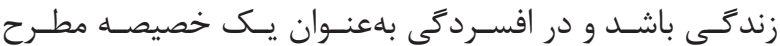

مىشــود (V) (V)

\footnotetext{
${ }^{6}$ Williams

${ }^{7}$ Raec

${ }^{8}$ Memory specificity training

${ }^{9}$ Over general memory

${ }^{10}$ Behavioral activation
} 


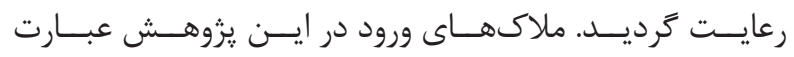

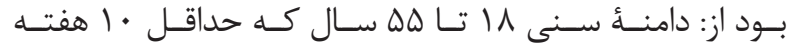

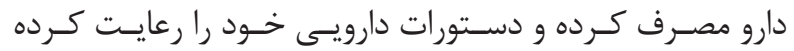

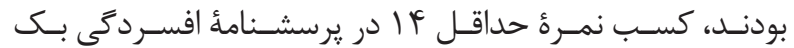

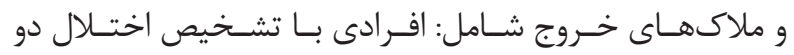

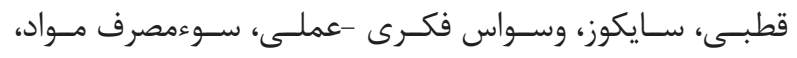

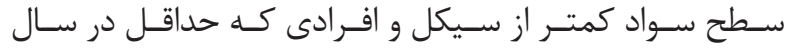

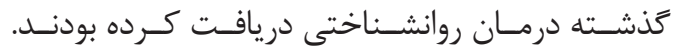

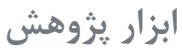

\section{يرسشنامهُ افسردگى بك ويرايش دوم (BDI-II)}

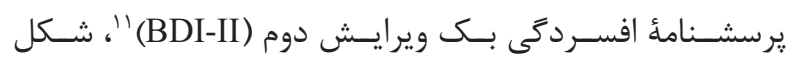

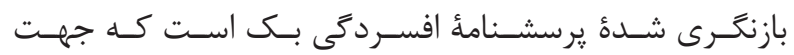

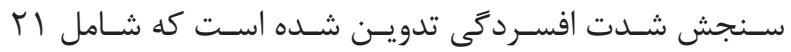

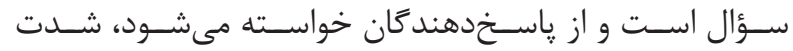

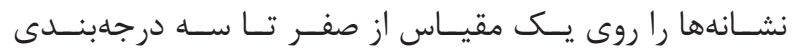

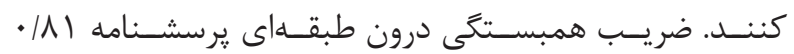

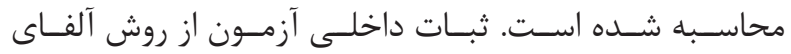

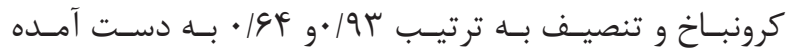

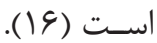

\section{مقياس ياسخهاى نشخوار فكرى}

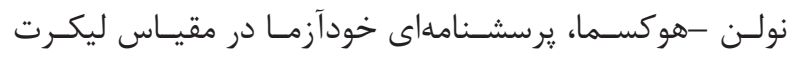

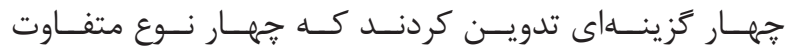

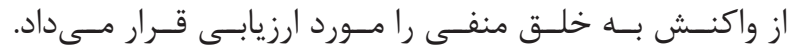

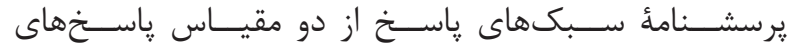

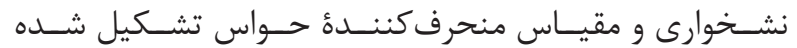

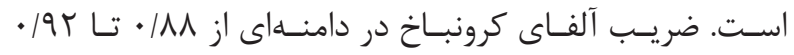

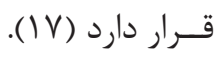

\section{مقياس نارسايى كنش نكرش}

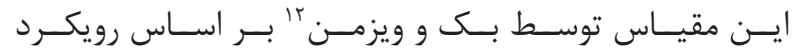

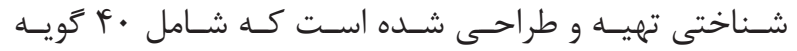

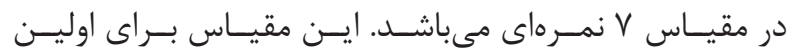

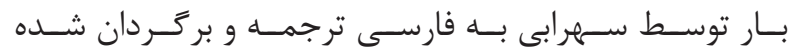

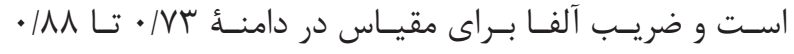

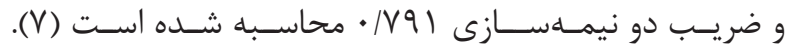

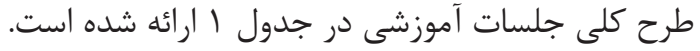

\section{درمان فعالسازى رفتارى كوتاهمدت}

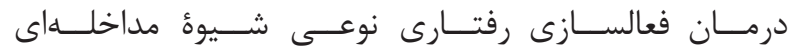

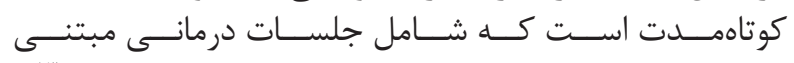

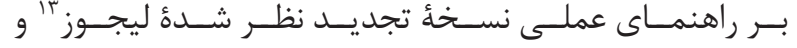

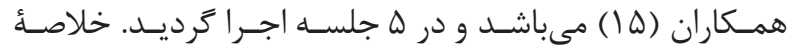

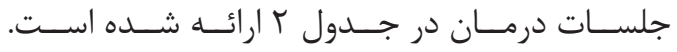

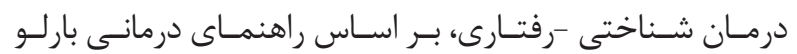

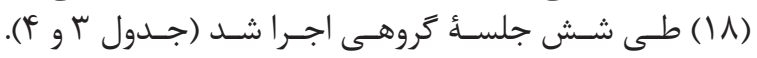

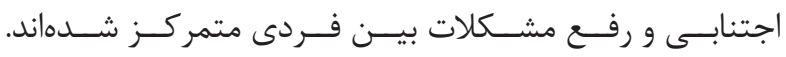

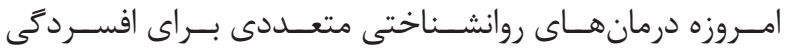

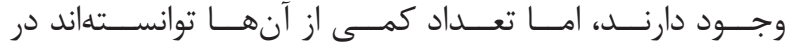

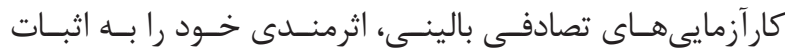

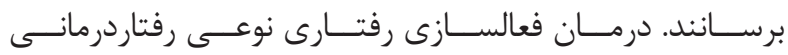

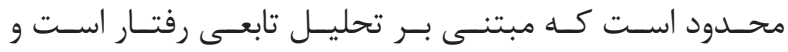

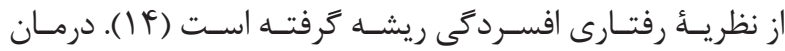

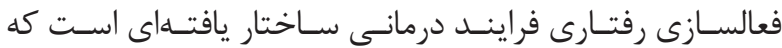

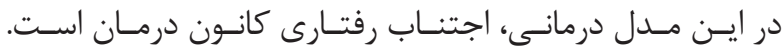

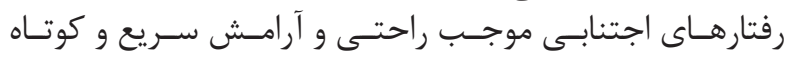

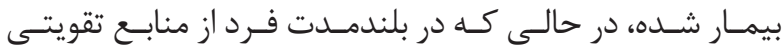

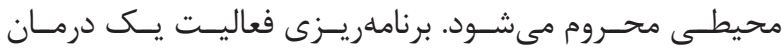

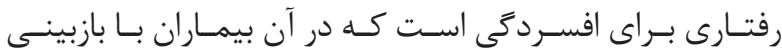

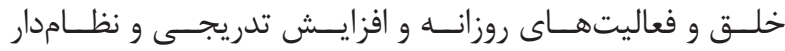

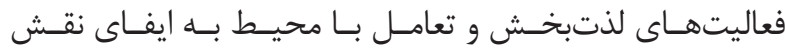

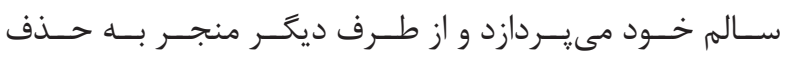

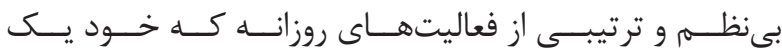

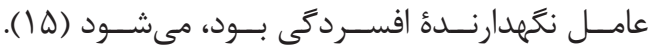

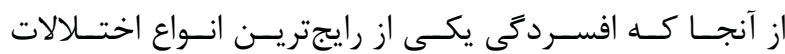

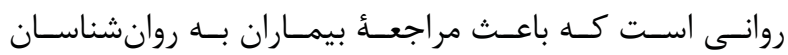

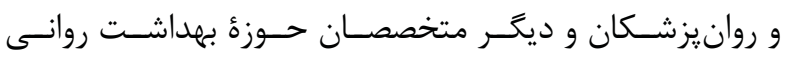

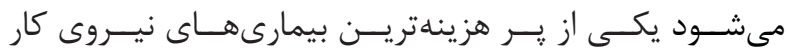

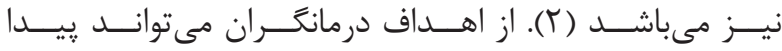

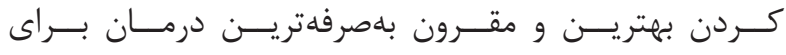

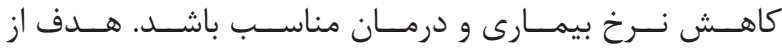

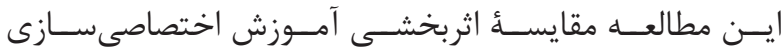

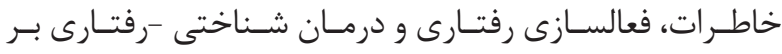

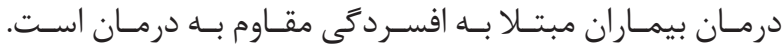

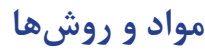

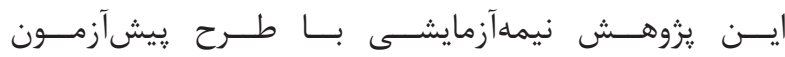

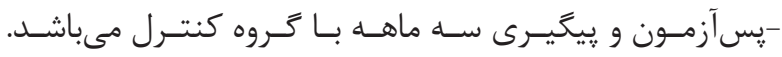

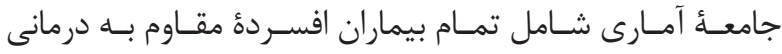

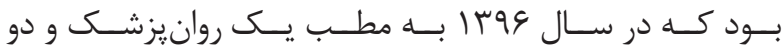

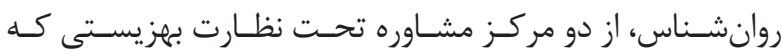

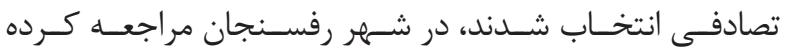

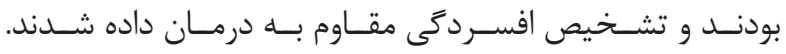

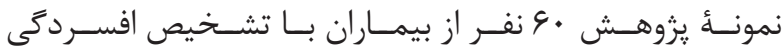

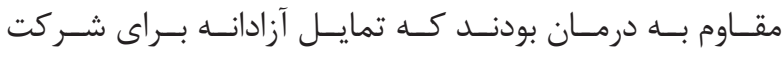

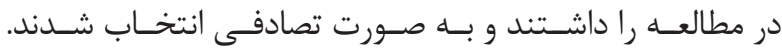

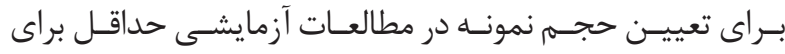

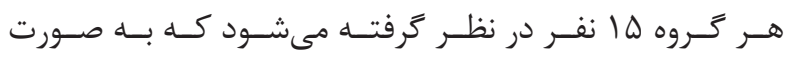

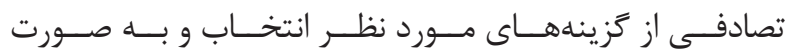

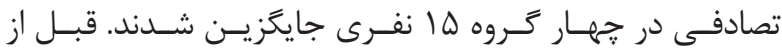

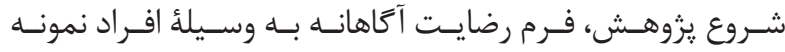

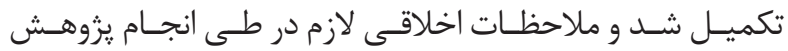

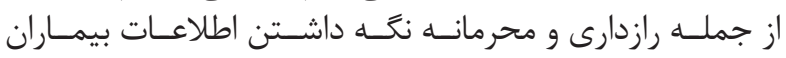


دادن اطلاعات دربارة افسردگى، توضيح عملكرد حافظه در افسردگى، بيان خاطرة اختصاصى با كلمات خنثى، تكاليف

ارائهُ خلاصهُ جلسهُ اول، مرور تكاليف خانكى، ارائهُ جزيئات بيشتر خاطرات، تكليف هفتهُ آينده (دو

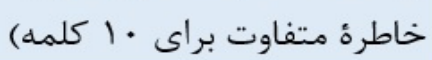
ارائهُ خلاصةُ جلسهُ دوم، تأكيد بيشتر بر كلمات منفى، تكليف خانكى مرور جلسهُ قبل، تكاليف خانكى، آحاهى فراشناختى، يسآزمون و اتمام

这

جدول r- درمان فعالسازى رفتارى كوتاهمت.

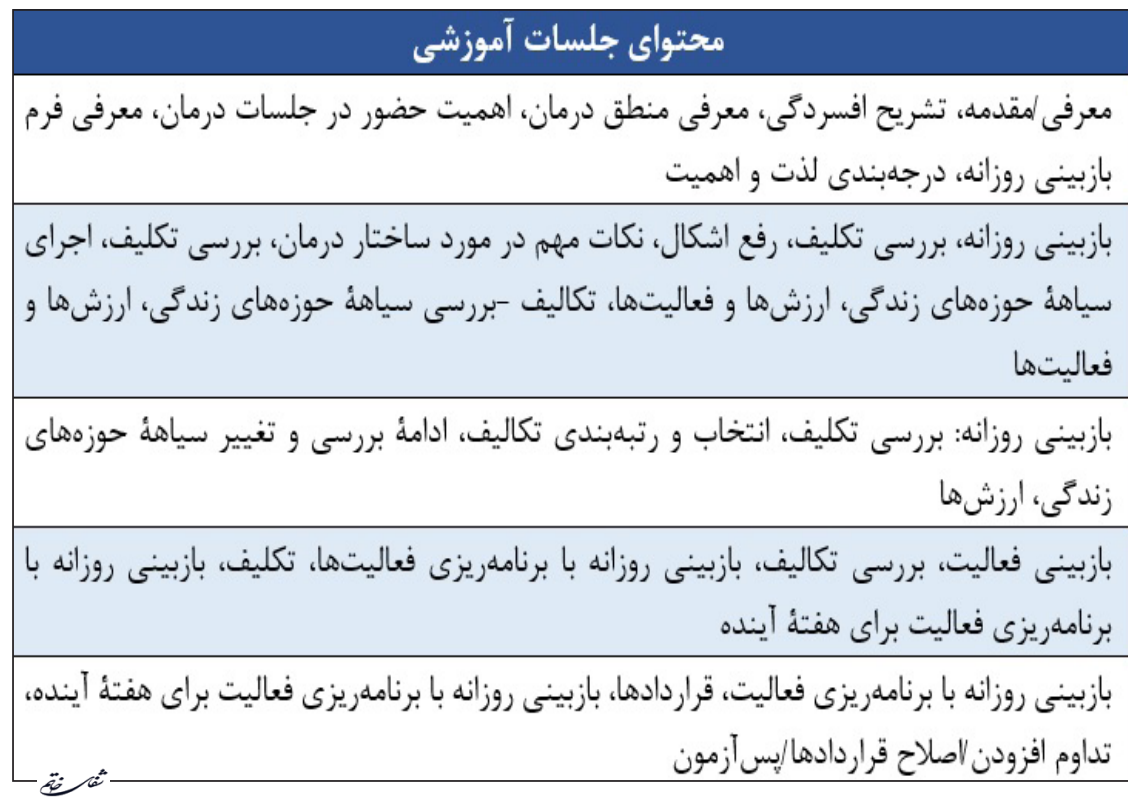

جلسات

جلسهُ اول

جلسة دوم

جلسة سوم

جلسه جهار م

حلسئ ينجمم

جدول بـ يروتكل درمان شناختى -رفتارى.

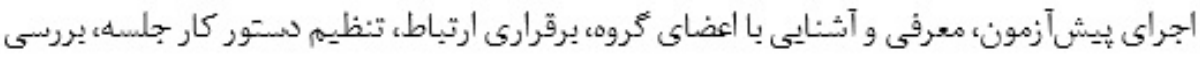

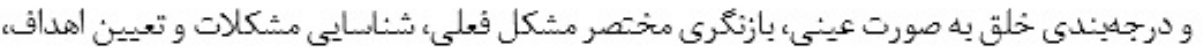

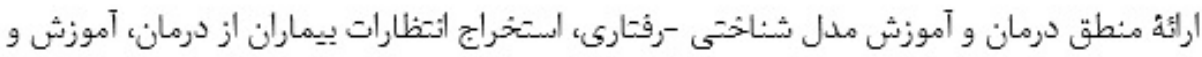
آشناسازى بيماران با الفسردكى، استخراج خلاصة نهائى و دريافت بازخورد و ارائه تكليف

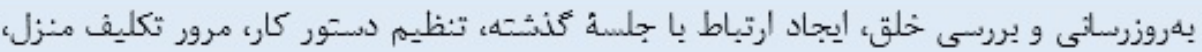
بحث در خحوص موارد مندرج در دستور كار، تعيين تكاليف جديد، تهيف خحلاصه ادوارى و تهية خلاصه نهائى و بازخورد و ارائه تكليف معرفى، توضيح و آشنا ساختن بيماران با اقكار خودوآيند و آموزش شناسائي افكار خودآيند، بررسى

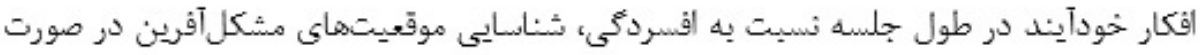

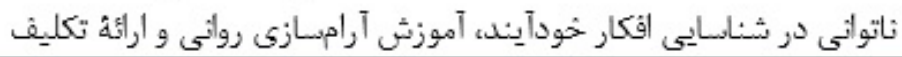

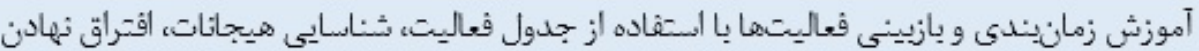

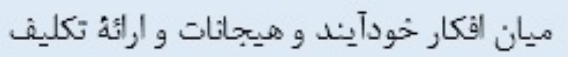

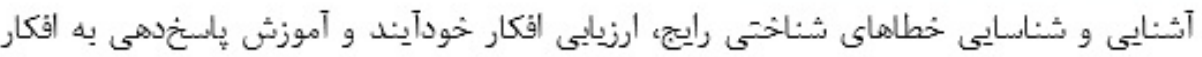

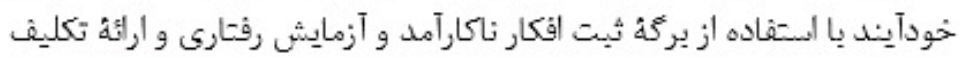
جلسة هنجم

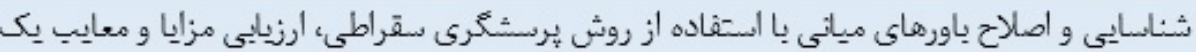

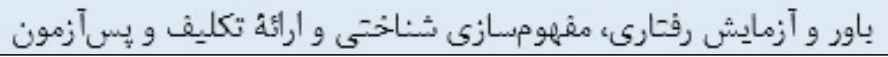




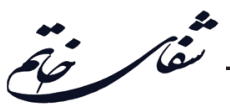

\begin{tabular}{|c|c|c|c|c|c|c|c|c|c|c|c|c|}
\hline \multicolumn{3}{|c|}{ سطح تحصيلات } & \multicolumn{4}{|c|}{ وضعيت التصادى } & \multicolumn{2}{|c|}{ جنسيت } & \multicolumn{3}{|c|}{ وضعيت تاهل } & متغير \\
\hline بالاى ديبلم & ديبلم & زيردييلم & عالى & خوب & متوسط & ضعيف & مرد & زن & مطلقه & متاهل & مجرد & فر اواثى \\
\hline \& & $\Lambda$ & 1 & 1 & $\Delta$ & 9 & + & $r$ & ir & 1 & 1. & $f$ & كردن خاطرات آختصاصى \\
\hline 1. & $\Delta$ & . & . & 4 & $\Lambda$ & 1 & $r$ & ir & . & ir & $r$ & فعالسازى رفتارى \\
\hline 9 & $\Delta$ & 1 & 1 & f & 1. & . & f & 11 & . & ir & $r$ & درمانى شناختى - \\
\hline 9 & f & r & . & f & 9 & r & $r$ & ir & 1 & 11 & $r$ & كثترل \\
\hline
\end{tabular}

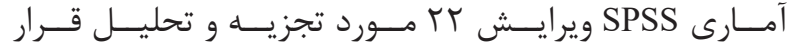

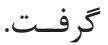

يافتهها

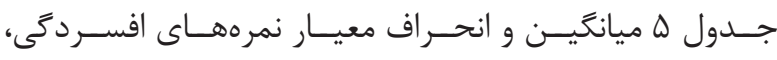

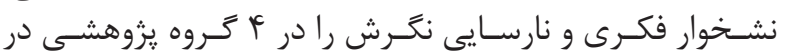

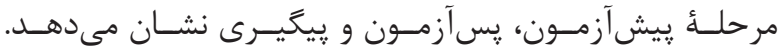

تجزيه و تحليل دادهها

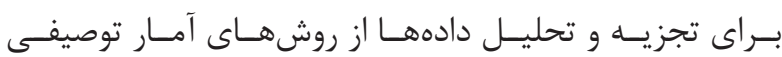

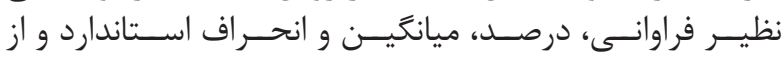

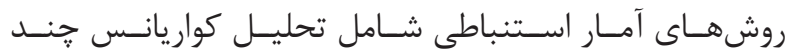

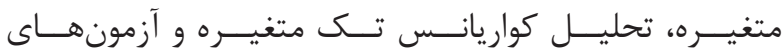

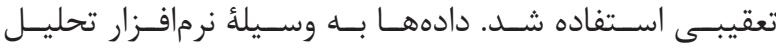

جدول ه- ميانكَين و انحراف معيار كروهها در متغيرهاى افسردگى، نشخوار فكرى و نارسايى نخرش.

\begin{tabular}{|c|c|c|c|c|c|c|c|}
\hline \multicolumn{2}{|c|}{ نارسايى نكُش } & \multicolumn{2}{|c|}{ نشخوار فكرى } & \multicolumn{2}{|c|}{ افسردكى } & & \multirow{2}{*}{ متغير } \\
\hline أحراف معيار & ميانكين & أحراف معيار & ميانكين & أنحراف معيار & |ميانكَين & & \\
\hline$r / \Delta \Lambda$ & $91 / 4 V$ & $9 / 1 \pi$ & DI/DT & $V / \Gamma$. & $\forall N / \cdot$ & يَيشآزمون & آموزش \\
\hline g/4. & $k q / * q$ & $\mathrm{~V} / \mathrm{l} \Lambda$ & $r \cdot / \Lambda \varphi$ & $F / \Delta$ & $1 \cdot 11$. & پِ آزمون & اختصاصى كردن \\
\hline$r / 1 \Delta$ & $19 / 48$ & $\varphi / 19$ & WNTE & $r / \omega$. & $1 . / \cdot$ & يَيَّيرى & خاطرات \\
\hline$\Delta / r q$ & $9 N 1 \cdot 9$ & $N \& D$ & $\notin \varepsilon \mid .$. & D/T & $\Delta 1 / \wedge 9$ & يَيشآزمون & \\
\hline G/VT & $\Delta r / T r$ & $1 \cdot 119$ & $r F / T$. & $9 / \pi 9$ & $\mid r / 1 T$ & پِسآزمون & فعالسازى رفتارى \\
\hline$r / \Delta T$ & $r V / \Delta T$ & $\Gamma / 9 \Lambda$ & $T V / T$. & $\Gamma / \Delta \varphi$ & $\mid F / \pi$. & بيگيُى & \\
\hline$V / G$. & $\Delta q / \cdot \cdot$ & $N / \&$ & $\varphi q \mid .$. & $\Gamma / \Lambda$ & FV/rg & يُيشآزمون & \\
\hline$r\left|/ \varphi^{\prime}\right|$ & TI/TAV & 9/1T & $r \mu / \Lambda$. & $9|4|$ & $r \cdot / \cdot \cdot$ & يَسآزمون & \\
\hline$\Delta / \Delta r$ & $r 1 / \cdot 9$ & $0 / 99$ & $r T / \Lambda 9$ & g/rV & $I V / \Lambda .$. & بيَّيرى & \\
\hline$r / / 4 \Delta$ & $V \Delta / \cdot \cdot$ & $9 / 0$ & $0 \cdot 4$. & p/qVD & $\Delta F / q T$ & يُيشآزمون & \\
\hline$\Delta / \Delta$. & $\Delta r / q T$ & F/TV & FNG. & $1 \% / \Delta 9$ & $r V / q r$ & پِسآزمون & كنترل \\
\hline p/qr & $k F / 4$ & SIVA. & $\Delta 1 / 9$. & $11 / \cdot r$ & re/A. & بيَّيرى & \\
\hline
\end{tabular}




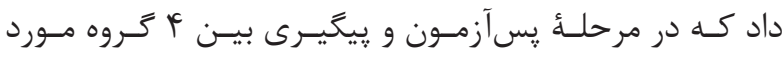

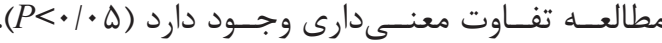

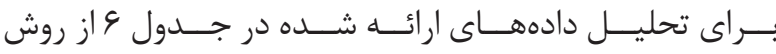

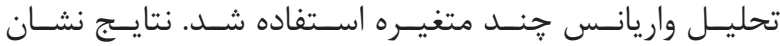

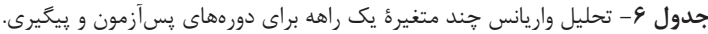

\begin{tabular}{|c|c|c|c|c|c|c|c|}
\hline معثىدارى سطع & F & مجيانُّين & df & مجذورات مجموع & \multicolumn{2}{|c|}{ متغيرها } & منبع \\
\hline$\cdot / \cdots$ & & $19+1 / 99$ & $r$ & $\triangle \triangle Q N / Q V$ & افسردمّى & \multirow{3}{*}{ يسآزمون } & \multirow{6}{*}{ كرومها } \\
\hline$* / *$ & $r F / T \lambda$ & $1 r+4 / \cdot 9$ & $r$ & एवसा/•V & نشخوار فكرى & & \\
\hline$* *$ & 19/\%र & rV४৭१/Tr & $r$ & AIr.V/Ir & نارسايى نُّرش & & \\
\hline$* / \cdots$ & $f+1+r$ & $\mid \wedge F T / 90$ & $r$ & $\Delta \Delta / T / f$. & افسردمّى & \multirow{3}{*}{ يُينّيرى } & \\
\hline$* / \cdots$ & $1 / 94$ & & $r$ & $V+r \mid / T 1$ & نشخوار فكرى & & \\
\hline$* / *$ & VT/AV & IFGI/AG & $r$ & 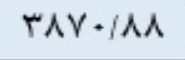 & نارسايى نُّرش & & \\
\hline- & - & $\mathrm{Va} / \mathrm{IV}$ & Fq & $r \Delta \wedge \Leftrightarrow / \Lambda \Delta$ & افسردمّى & \multirow{3}{*}{ يسآزمون } & \multirow{6}{*}{ خطا } \\
\hline - & - & $\Delta r / Q G$ & Fq & $|\Delta| Y / \cdot f$ & نشخوار فكرى & & \\
\hline - & - & $\mid$ TQN/T| & Fq & \&人VAN/QF & نارسايى نتّرش & & \\
\hline - & - & $f \Delta / 9)$ & $F 9$ & TYOV/IV & افسردّىى & \multirow{3}{*}{ بينحيرى } & \\
\hline- & - & TN/DS & Fq & $|\Delta| Y / \cdot F$ & نشخوار فكرى & & \\
\hline- & - & $1 V / 48$ & Fq & $9 r \cdot / r \cdot$ & نارسايى نُّرث & & \\
\hline
\end{tabular}

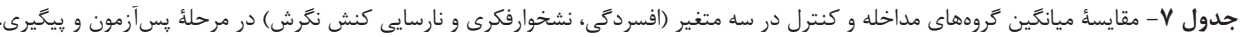

\begin{tabular}{|c|c|c|c|}
\hline سطح معثى & خطاى استاثدارد & تغاوت مياثخينها & ئروهماى مورد مقايسه \\
\hline & & & يس آزموث الفسردئى \\
\hline$\cdot / 9 \mathrm{~V}$ & $r / \cdot 9$ & $-1 / 4$ & اختصاصىسازى خاطرات -فعالسازى رفتارى \\
\hline$\cdot 1 \cdot 4$ & $5 / 19$ & $-9 / 4$ & الختصاصى سازى خاطرات -درمان شتاختى -رفتارى \\
\hline$\cdot / \cdots$ & $r / \cdot 9$ & 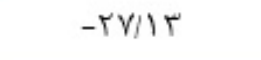 & الختصاصى سازى خخاطرات -مروه كثترل \\
\hline$\cdot 1 \cdot 9$ & r/4q & $-\mathrm{V} / \Lambda 9$ & فعالسازى رفتارى -نرمان شتاختي -رفتارى \\
\hline$* \cdots$ & r/ब & $-r Q / \Lambda$ & فأسازى رفتارى -كروه كثترل \\
\hline$\cdot \cdots$ & $r / \cdot A$ & $-1 V / 9 r$ & درمان ششاختى -رفتارى -كروه كثترل \\
\hline & & & 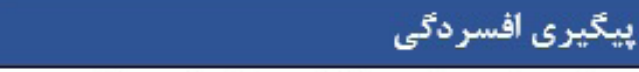 \\
\hline$\cdot / T f$ & $r / 4 A$ & $-f / t$ & اختصاصى سازى خاطرات فؤالسازى رفتارى \\
\hline$\cdot / \cdot 1$ & $r / f \wedge$ & $-V / \Lambda \Delta$ & الختصاصى سازى خاطرات -درمان شتاختى -رفتارى \\
\hline$\cdot / \cdots$ & $r / 4 A$ & $-r q / \Lambda \cdot$ & الختصاصى سازى خاطرات -تحروه كترل \\
\hline$\cdot / f V$ & $r / f \wedge$ & $-\pi / 9$. & فتالسازى رفتارى -نرمان شتاختي -رفتارى \\
\hline$\cdot / \cdots$ & $r / 4 A$ & $-t T / e_{0}$ & فعالسازى رفتارى -كروه كثترل \\
\hline$\cdot 1 \cdots$ & $r / f \wedge$ & $-19 / \cdot 9$ & درمان شتاختى -رفتارى -تمروه كتترل \\
\hline
\end{tabular}




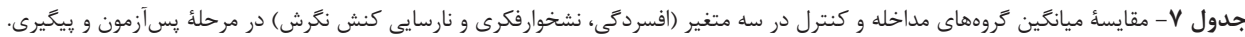

\begin{tabular}{|c|c|c|c|}
\hline & & & بسآزمون ثشخوار فكرى \\
\hline$\%$ & r/VG & 每 & اختصاصى سازى خاطرات فئالسازى رفتارى \\
\hline$\cdot / V \mid$ & $r / 98$ & $-r / 94$ & اختصاصى سازى خاطرات -درمان شثاختى -رفتارى \\
\hline$\%$ & $r / \Delta \varphi$ & $-4 R / V t$ & اختصاصىسازى خاطرات -كروه كثترل \\
\hline.$/ .4$ & $r / f \Delta$ & $1 \cdot / 4 \cdot$ & فعالسازى رفتارى -درمان شتاختى -رفتارى \\
\hline$\%$ & t/VG & $-\mid f / f$. & فئالسازى رفتارى -كروه كثترل \\
\hline$\% \cdots$ & T/VO & $-r f / 4$. & درمان شتاختى -رفتارى -كروه كتترل \\
\hline & & & بيَيَيرى نشخوار فكرى \\
\hline$\%$ & $1 / 99$ & $-N / 94$ & اختصاصى سازى خاطرات فقعالسازى رفتّارى \\
\hline$\cdot /$ & $1 / 91$ & $-f / 9$. & اختصاصى سازى خاطرات -درمان شثاختى -رفتارى \\
\hline$\cdot \cdots$ & I/AV & 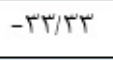 & اختصاصىسازى خاطرات -كروه كثترل \\
\hline$\cdot / 1 f$ & $1 / 99$ & f/rt & فعالسازى رفتارى -درمان شتاختى -رفتّارى \\
\hline$\cdot \cdots$ & $1 / 19$ & thfit. & فعالسازى رفتارى -مُروه كثترل \\
\hline$\%$ & $1 / 9 v$ & $-r N R T$ & درمان شثاختى -رفتتارى -كروه كتترل \\
\hline & & & 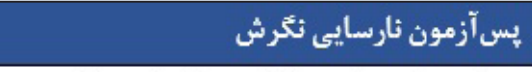 \\
\hline$\cdot / \cdot \Delta$ & $1 \% / T \Delta$ & $-r f / \Delta r$ & اختصاصى سازى خاطرات فقعالسازى رفتتارى \\
\hline$\cdot 1 \cdot 1$ & IT/KF & $-f f / f g$ & اختصاصىسازى خاطرات -درمان شثاختى -رفتارى \\
\hline$\cdot / \cdots$ & $|r / \pi|$ & $99 / 19$ & الختصاصىسازى خاطرات -مروه كثترل \\
\hline$\cdot / A V$ & $1 \% / r \Delta$ & $-9 / 94$ & فعالسازى رفتارى -درمان شتاختىى -رفتارى \\
\hline$\% \cdots$ & $15 / 19$ & $10 / 1$ & فئسازى رفتارى -مروه كثترل \\
\hline$\%$ & $1 T / 4 \Delta$ & $19 / \mathrm{rr}$ & درمان شتاختى -رفتارى -مروه كتترل \\
\hline & & & بييَيرى نارسايى نثرش \\
\hline$\%$ & 1/Or & $-11 / \cdot 9$ & اختصاصىسازى خاطرات فُعالسازى رفٔتارى \\
\hline 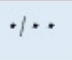 & l/rf & $-14 / 9$. & اختصاصى سازى خاطرات -درمان شثاختى -رفتارى \\
\hline$\cdot \%$ & $1 / \Delta r$ & $-r N \cdots$ & اختصاصىسازى خاطرات -كروه كثترل \\
\hline$\cdot / 14$ & $1 / f V$ & $-r / \Delta r$ & فيالسازى رفتارى -درمان شثانختى -رفتّارى \\
\hline$\cdot \cdots$ & $1 / \Delta T$ & $-19 / 94$ & فوالسازى رفتارى -كروه كثترل \\
\hline$\% \cdots$ & $1 / \Delta \Lambda$ & $-1 \% / 4 \cdot$ & درمان شتاختى -رفتارى -كروه كتترل \\
\hline
\end{tabular}

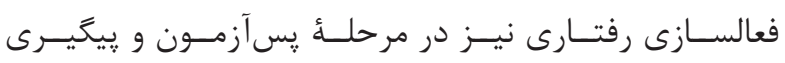

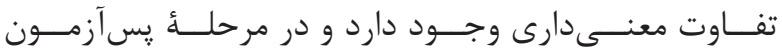

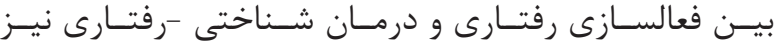

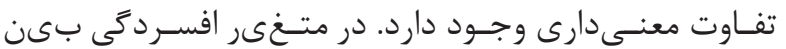

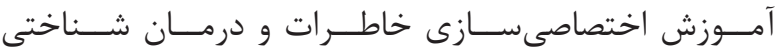

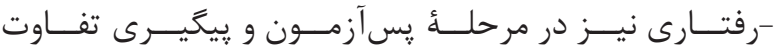

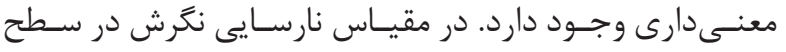

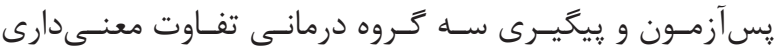

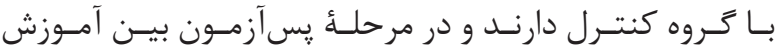

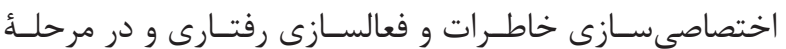

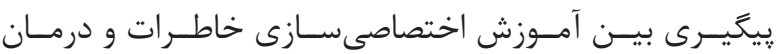

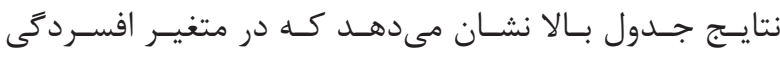

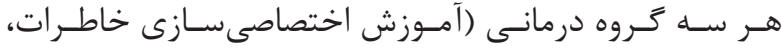

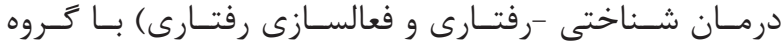

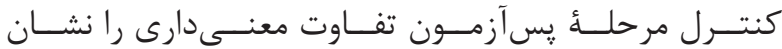

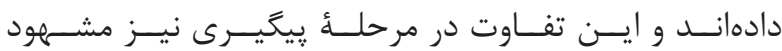

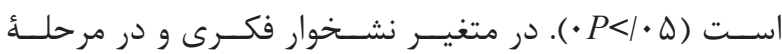

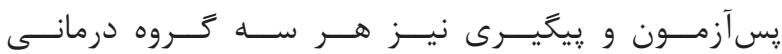

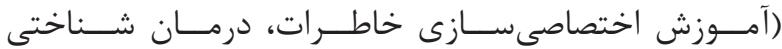

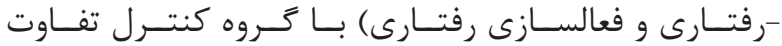

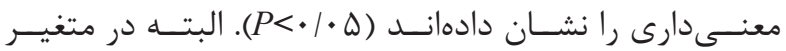

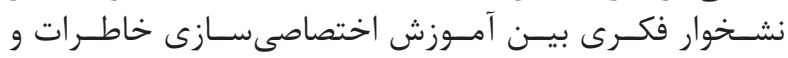




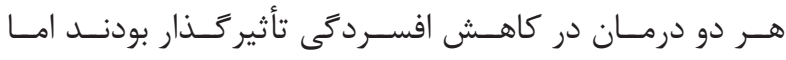

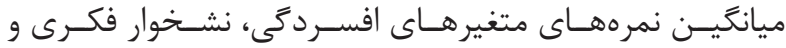

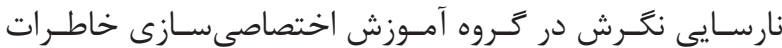

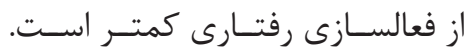

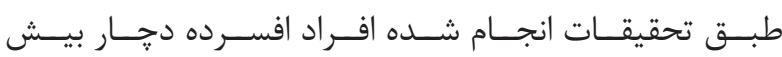

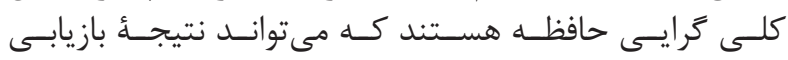

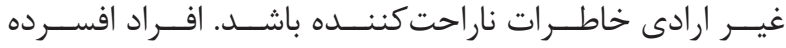

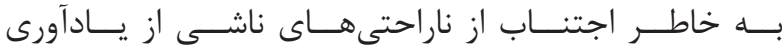

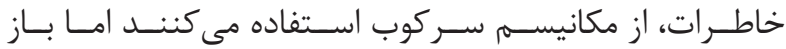

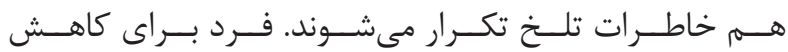

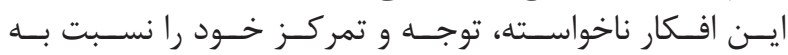

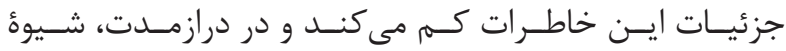

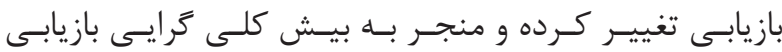

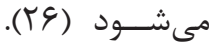

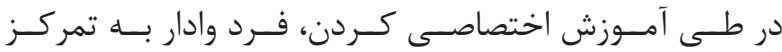

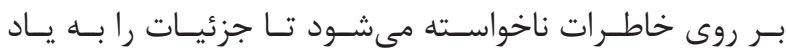

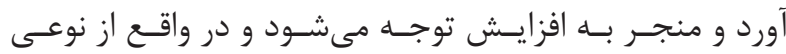

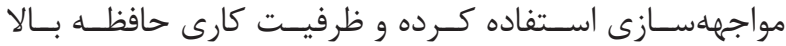

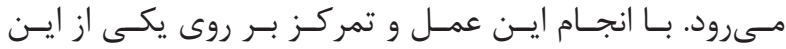

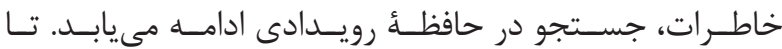

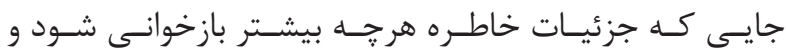

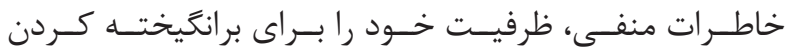

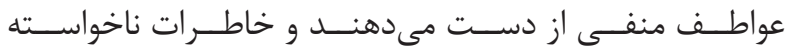

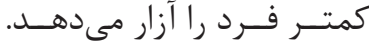

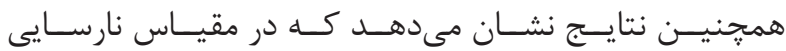

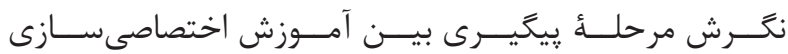

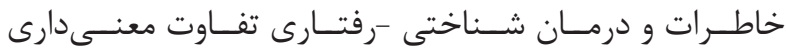

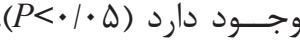

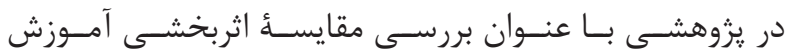

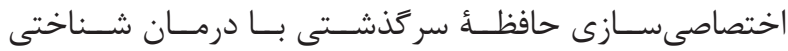

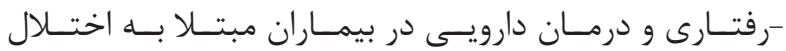

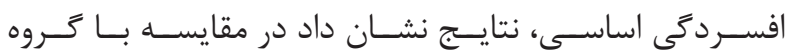

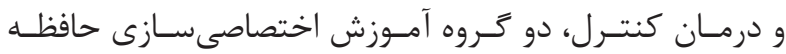

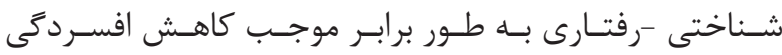

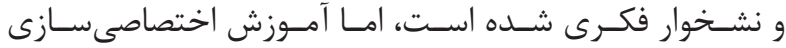

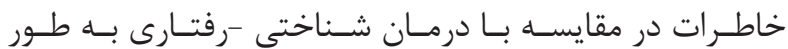

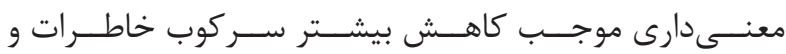

افزايسش خاطــرات اختصاصسى شـــه اسـت (YV)

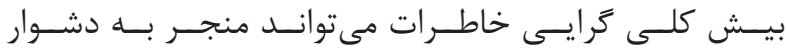

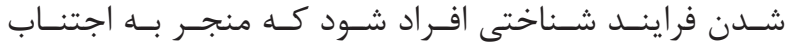

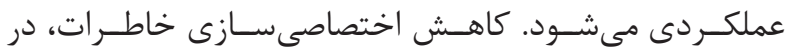

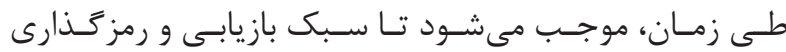

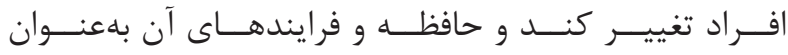

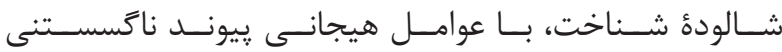

شــناختى -رفتـارى و فعالســازى رفتـارى تفــاوت معنسى دارى

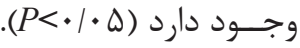

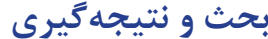

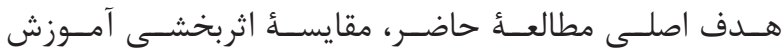

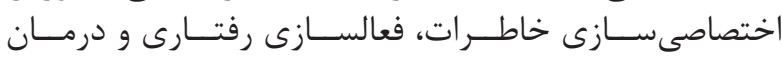

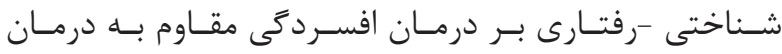

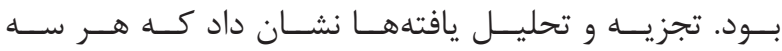

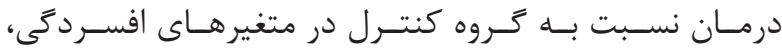

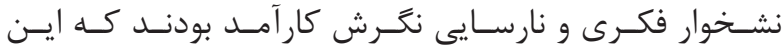

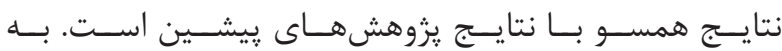

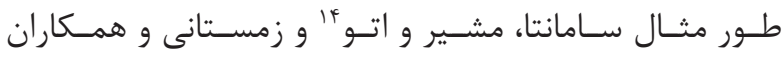

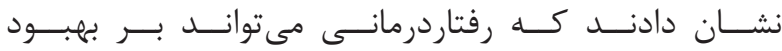

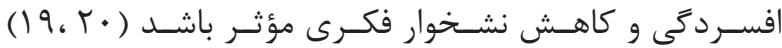

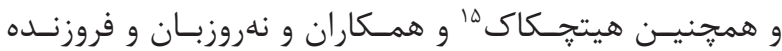

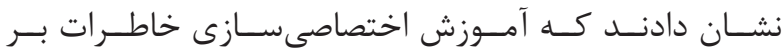

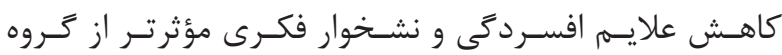

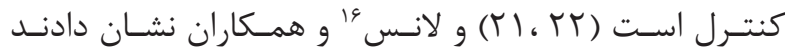

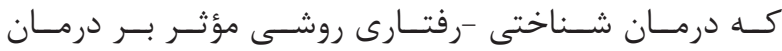

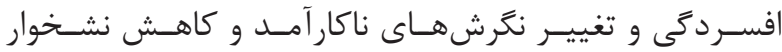

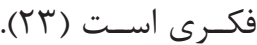

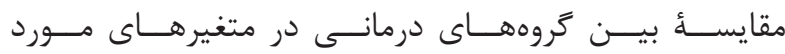

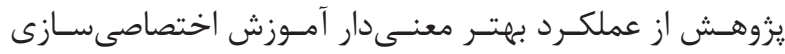

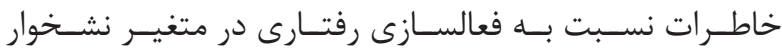

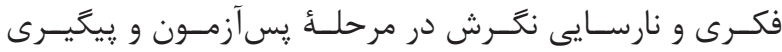

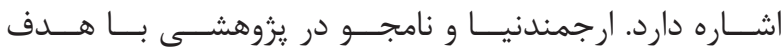

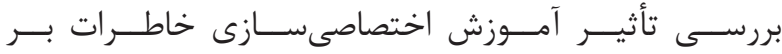

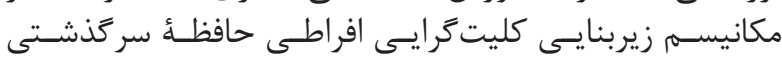

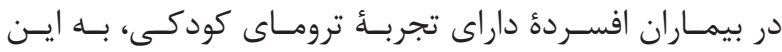

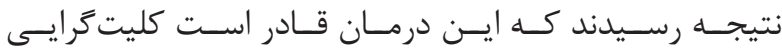

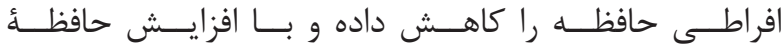

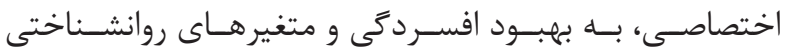

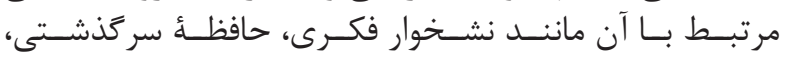

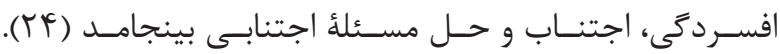

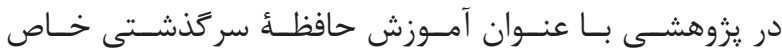

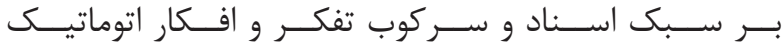

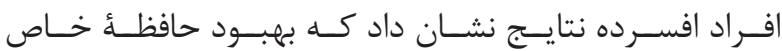

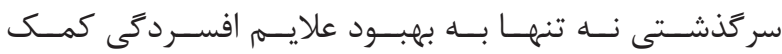

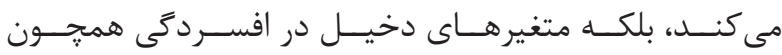

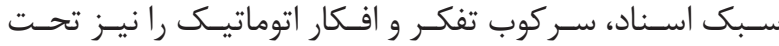

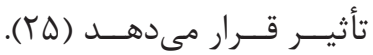

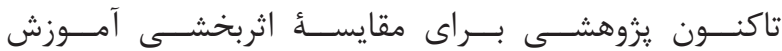

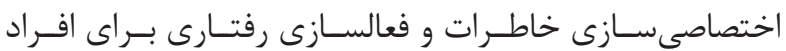

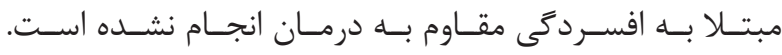

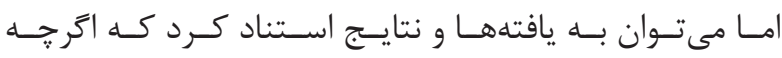

${ }^{14}$ Samantha, Moshier and Otto

${ }^{16}$ Lance 


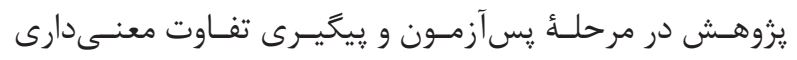

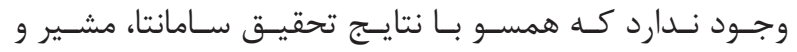

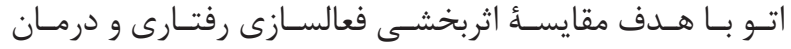

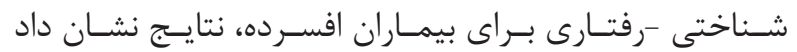

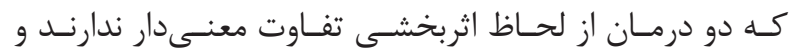

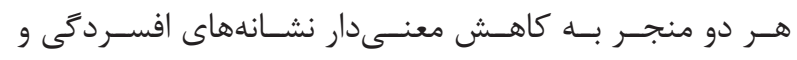
نشــخوار مىشــــن (19 (1).

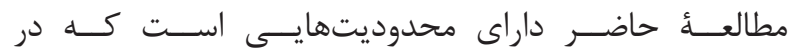

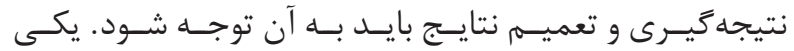

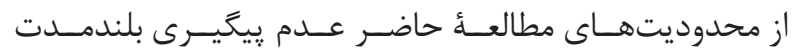

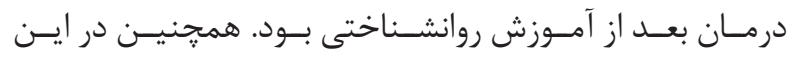

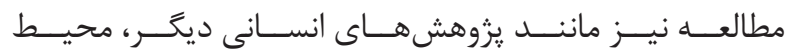

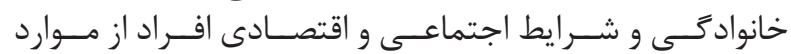

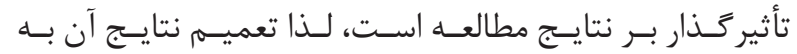

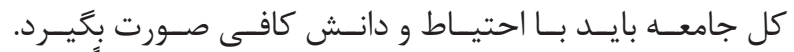

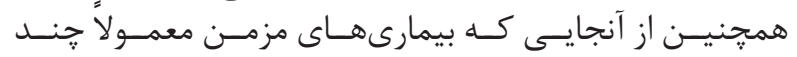

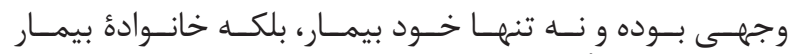

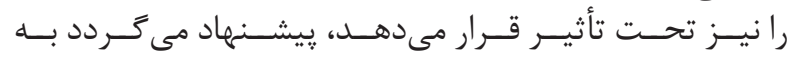

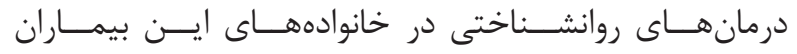

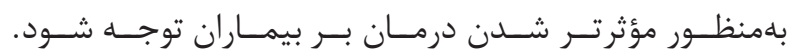

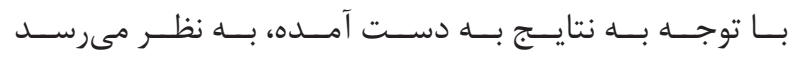

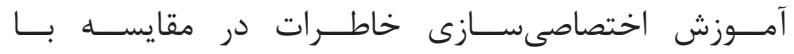

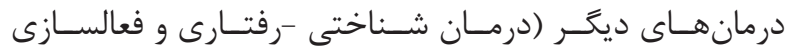

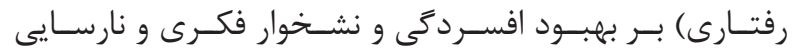

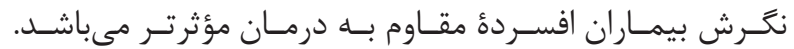

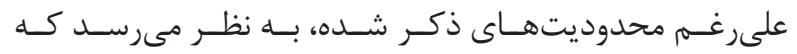

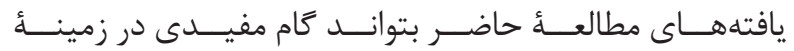

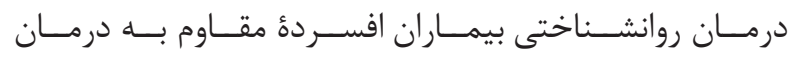

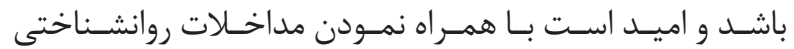

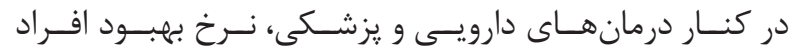

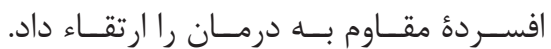

$$
\text { تشكر و قدردانى }
$$

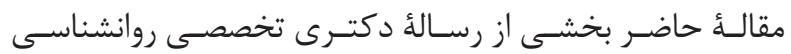

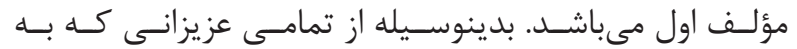

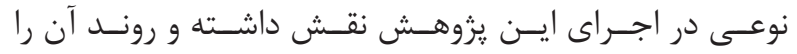

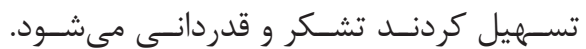

1. World Health Organization. Mental and neurological disorders. http://www.who.int/mediacentre/factsheets / fs265/en/. 2001.

2. Kessler RC, Bromet EJ. The epidemiology of depression across cultures. Annu Rev Public Health. 2013; 34: 119-38.

\section{Belmaker RH, Agam G. Major depressive disorder. N}

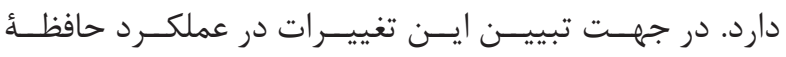

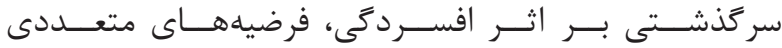

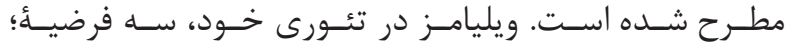

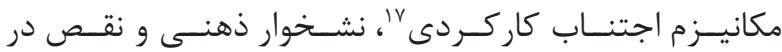

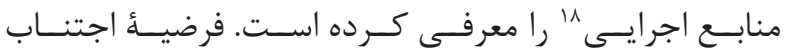

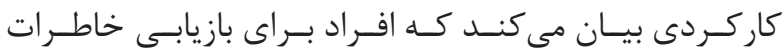

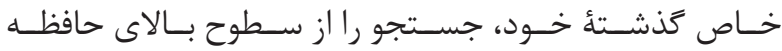

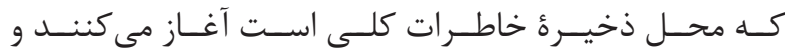

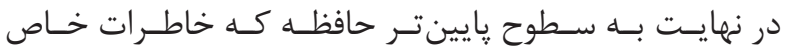

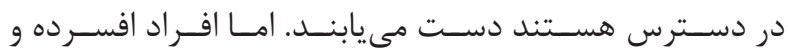

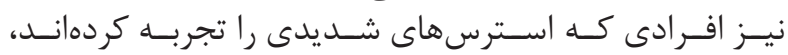

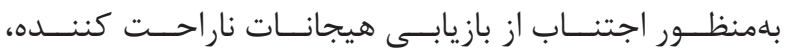

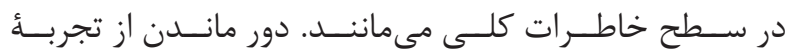

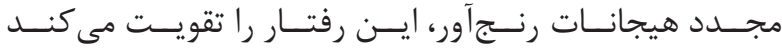

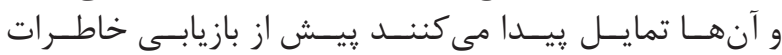

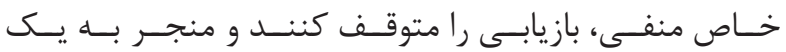

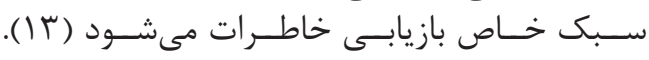

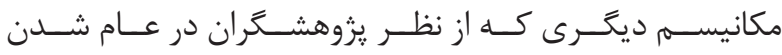

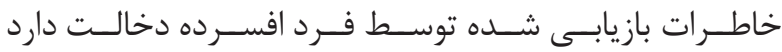

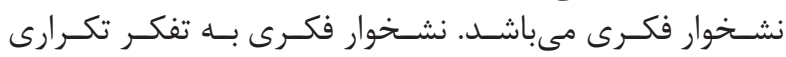

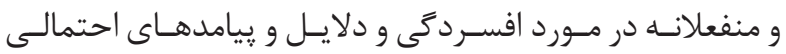

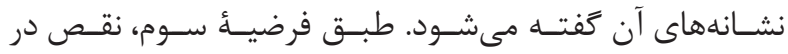

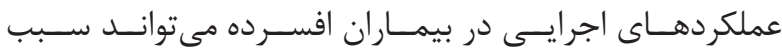

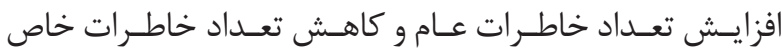

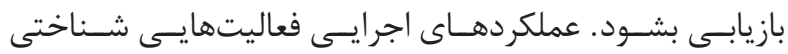

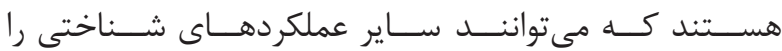

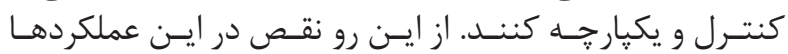

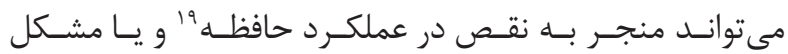

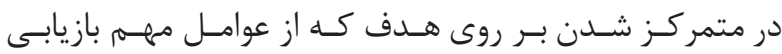

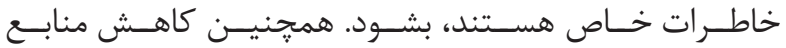

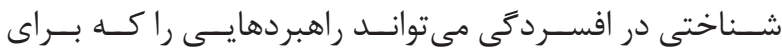

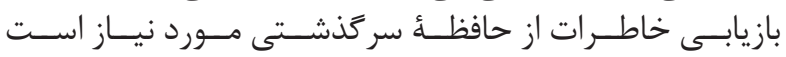

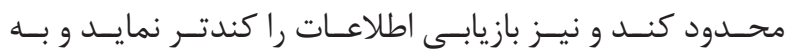

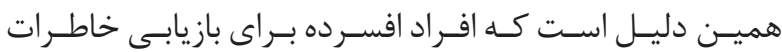

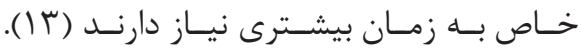

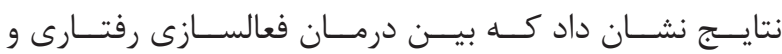

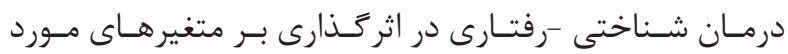
منابع

Engl J Med. 2008; 358(1): 55-68.

4. Fava M. Diagnosis and definition of treatment-resistant depression. Biol Psychiatry. 2003; 53(8): 649-59.

5. Wijeratne C, Sachdev P. Treatment-resistant depression: critique of current approaches. Aust N Z J Psychiatry. 2008; 42(9): 751-62.

\footnotetext{
${ }^{17}$ Functional avoidance

${ }^{18}$ Executive resource

${ }^{19}$ Memory function
} 
6. Emery G. Overcoming depression: a cognitive behavior protocol for the treatment of depression. USA: New Harbinger Publication. 2000; p. 145-89.

7. Sohrabi N. Psychometric indexes of attitude-deficit scale. Journal Psychological Methods and Models. 2016; 19(6).

8. Watkins ED, Baracaia S. Why do people ruminate in dysphoric moods? Per Indiv Differ. 2001; 30(5): 723-34.

9. Joormann J. Differentioal effect of rumination and dysphoria on the inhibitionof irrelevant emotional material: Evidance from a negative priming task. Cognitive Therapy and Research. 2006; 30(4): 149-60.

10. Neshat-Doost HT, Dalgleish T, Golden A-MJ. Reduced specificity of emotional autobiographical memories following self-regulation depletion. Emotion. 2008; 8(5): 731-6

11. Werner-Seidler A, Moulds ML. Autobiographical memory characteristics in depression vulnerability: formerly depressed individualsrecall less vivid positive memories. Cogn Emot. 2011; 25(6): 1087-103.

12. Conway KP, Compton W, Stinson FS, Grant BF. Lifetime comorbidity of DSM-IV mood and anxiety disorders and specific drug use disorders: results from the national epidemiologic survey on alcohol and related conditions. J Clin Psychiatry. 2006; 67(2): 247-57.

13. Williams JM, Barnhofer T, Crane C, Hermans D, Raes F, Watkins E, et al. Autobiographical memory specificity and emotional disorder. Psychological Bulletin. 2007; 133(2): 122-48.

14. Raes F, Williams GM, Hermans D. Reducing cognitive vulnerability to depression: A preliminary investigation of Memory Specificity Training (MEST) in inpatients withdepressive symptomology. J Behav Ther Exp Psychiatry. 2009; 40: 24-38.

15. Lejuez CW, Hopko DR, Hopko SD. Ten-year revision of the brief behavioral activation treatment for depression (BATD): revised treatment15- manual (BATD-R). Behavior Modification. 2011; 35: 111-61.

16. Dobson KS, Mohammad Khani P. Psychometric characteristics of beck depression inventory-II in patients with major depressive disorder. J Rehab. 2007; 121(29): 82-9.
17. Nolen-Hoeksema $\mathrm{S}$. The role of rumination in depressive disorders and mixed anxiety/depressive symptoms. J Abnorm Psychol. 2000; 109(4): 504-11.

18. Barlow DH. Clinical handbook of psychological disorders: A step-by-steptreatment manual. New York: Guilford publications. 2014.

19. Samantha SJ, Otto MW. Behavioral activation treatment for major depression: A randomized trial of the efficacy of augmentation with cognitive control training. J Affect Disord. 2017; 210)1): 265-8.

20. Zemestani M, Davvodi I, MehrabiZade M, Zargar Y. The effectiveness of group behavioral activation therapy on depression, anxiety, and ruminating symptoms in patients with depression and anxiety. Clincal Psychology Journal. 2012; 4(5): 17-23.

21. Hitchcock C, Hammond E, Rees C, Panesar I, Watson $\mathrm{P}$, Werner-Seidler A, et al. Memory flexibility training to enhance memory specificity and reducedepressive symptomatology in individuals with major depressive disorder:study protocol for a randomised controlled trial. Trials. 2015; 16: 494. doi: 10.1186/s13063-015-1029-y.

22. Nerozbehan M, Forozande E. Investigating the effect of specific memory training on depression and depression of depressed girls. Health Journal. 2016; 5(12): 287-96.

23. Hawley LL, Padesky CA, Hollon SD, Mancuso E, Laposa JM, Brozina K, et al. Cognitive behavior therapy for Depression Using Mind Over Mood: CBT Skill Use and Differential Symptom Alleviation. Behav Ther. 2017; 48(1): 29-44.

24. Arjmandnia A, Namjo S. The effect of memorizing specialized education (meat) on the influential mechanisms of the extreme clinicalism of story memory in depressed patients with childhood traumatic experience. Journal of Isfahan Medical School. 2016; 33(329).

25. Forozande E, Ranjbarkohen Z. Special events memory and depression: a preliminary study. Quarterly Journal of Psychology and Educational Sciences. 2015; 2(8).

26. Hermans D, Defranc A, Raes F, Williams JMG, Eelen P. Reduced autobiographical memory specificity as an avoidant coping style. British Journal of Clinical Psychology. 2005; 44(4): 583-9. 